\title{
The temperature effect of cable-stayed bridge
}

\author{
Chenkongliang ${ }^{1, a}$, Wangronghui ${ }^{2, b}$ \\ ${ }^{1}$ School of Civil Engineering and architecture, WuYi University ,Jiangmen, China \\ ${ }^{2}$ School of Civil Engineering and Transportation, South China University of Technology,Guangzhou, \\ China \\ ackongliang@163.com, brhwang@scut.edu.cn,
}

Keywords: temperature field; element; model; thermal analysis

Abstract: by establishment of Midas FEA model and combining with the characteristics of temperature field, the research is carried out on temperature field, it shows that temperature field of the plates inside and outside surface is in the time lag relationship, and thermophysical properties of concrete is little effect on temperature field of the concrete beam.

\section{Introduction}

Temperature effects ${ }^{[1-12]}$ are more complex and uncertain for the cable-stayed bridge, which are related to natural environment, construction conditions and construction technology as well as other relevant factors, and temperature effects is very important for structural stress and deformation. The surface and internal points of the temperature are changing, which depends on the geographical location, structure and location of the season, solar radiation intensity, temperature changes, clouds, fog, rain and other weather conditions., so the temperature load in terms of its effect on the cable-stayed bridge is a more important influence.

\section{Modeling and calculation}

With the development of computing technology, structural analysis has been a great breakthrough. Midas FEA thermal analysis is based on the heat balance equation of energy conservation principle to calculate the temperature of each node and derive other thermal physical parameters by using the finite element method.

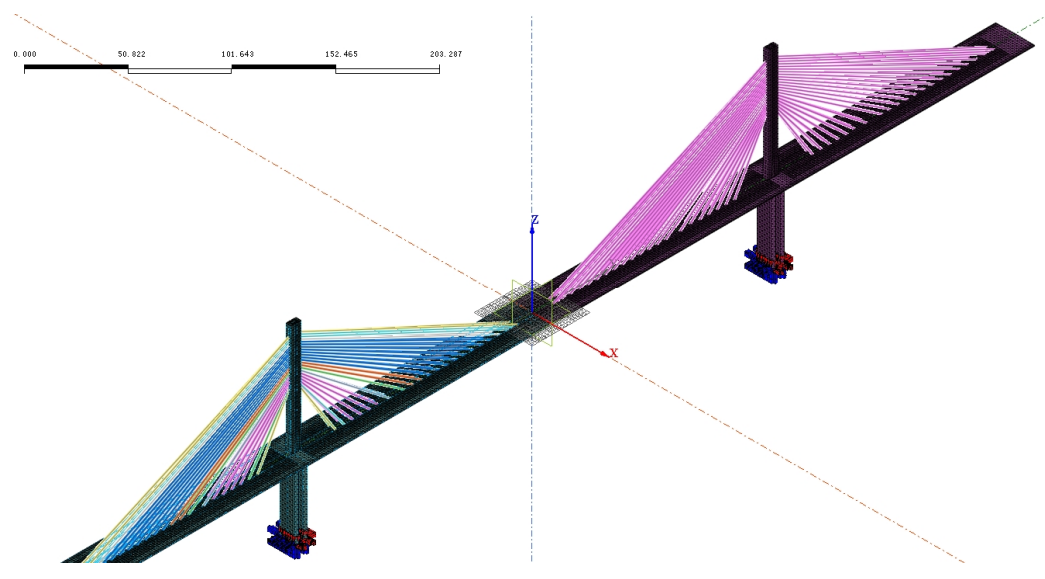

Fig. 1 thermal analysis Model 
Based on Yamen Bridge $(50+115+338+115+50)$, the structural model is built as follows: and the maximum size of the cross-section is $0.05 \mathrm{~m}$, and the elements are shown in Fig. 6.

Due to limitations of the test conditions, the parameters of the concrete are choosed according to specifications, and the bulk density of concrete is $2500 \mathrm{~kg} / \mathrm{m} 3$.

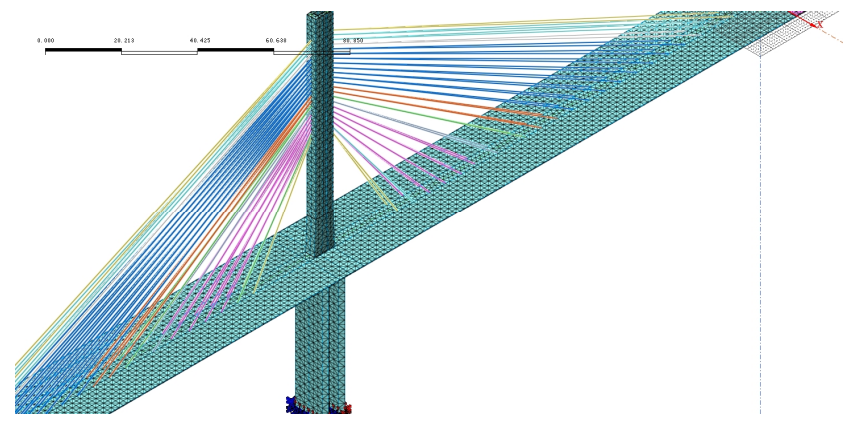

Fig. 2 The model of Yamen Bridge

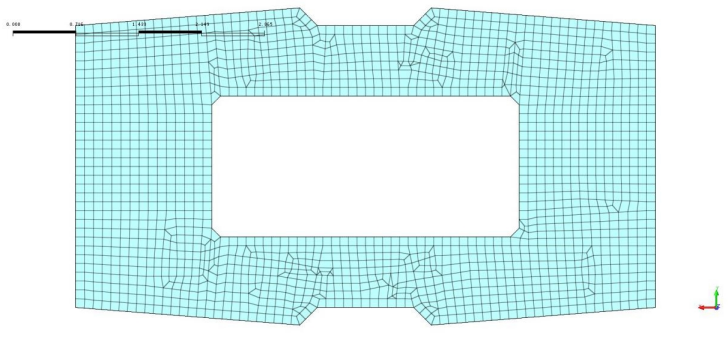

Fig.3 The unit division of Pier

\section{Temperature effect analysis}

Concrete beam is working under natural environmental conditions, and the factors of temperature field are including: external weather conditions, thermal physical properties of concrete and so on.

\section{Time transitive of temperature field}

Due to changes boundary conditions of the temperature field, concrete is a poor thermal conductivity of each of the plates which caused the temperature different with different time, and this phenomenon is time lag. According to the study showed that the air temperature and atmospheric temperatures of beam in accordance with the basic cosine curve.

$$
T=A \cos \omega t
$$

For two-dimensional heat conduction equation, and because the width of the plate is much larger than the thickness of the plate under normal circumstances, then the above equation can be simplified to one-dimensional problem equation, then we have

$$
\left\{\begin{array} { l } 
{ \frac { \partial T } { \partial t } = \beta ( \frac { \partial ^ { 2 } T } { \partial x ^ { 2 } } + \frac { \partial ^ { 2 } T } { \partial y ^ { 2 } } ) } \\
{ \beta = \frac { k } { \rho c } }
\end{array} \left\{\begin{array}{l}
\frac{\partial T}{\partial t}=\beta \frac{\partial^{2} T}{\partial x^{2}} \\
\beta=\frac{k}{\rho c}
\end{array}\right.\right.
$$

Where: $T$ - the temperature of beam;

A-The amplitude of temperature;

$\omega$ - The related parameters of temperature cycle;

$\rho$ _density of concrete;

$c$ _-Specific heat of concrete ;

$\beta$ _Thermal diffusivity of concrete.

\section{Influence of thermal physical parameters on the temperature field}

Thermal conductivity is an important physical parameter of thermal physical parameters, and 
thermal conductivity and specific heat of concrete are mainly affected by concrete materials, including the type of sand and gravel aggregate, gravel and concrete aggregate amount of other factors.

The thermal conductivity of the concrete is the unit temperature difference of heat per unit time through unit area of the concrete, and specific heat of concrete is the specific heat per unit mass of body heat when the temperature required for the absorption of $1^{\circ} \mathrm{C}$. In most cases, due to the test site conditions, it is difficult to determine the thermal physical parameters of the concrete type of concrete used in the main beam, according to many domestic and foreign literature and norms are measured summed up by concrete thermal physics changes in the scope of parameters.

Concrete thermal physical parameters is changed so that the thermal conductivity $\mathrm{k}=1.5$

$\mathrm{W} / m \cdot{ }^{\circ} \mathrm{C}$ could be applied to the original model by calculating the results shown in Fig.4 and Fig.5

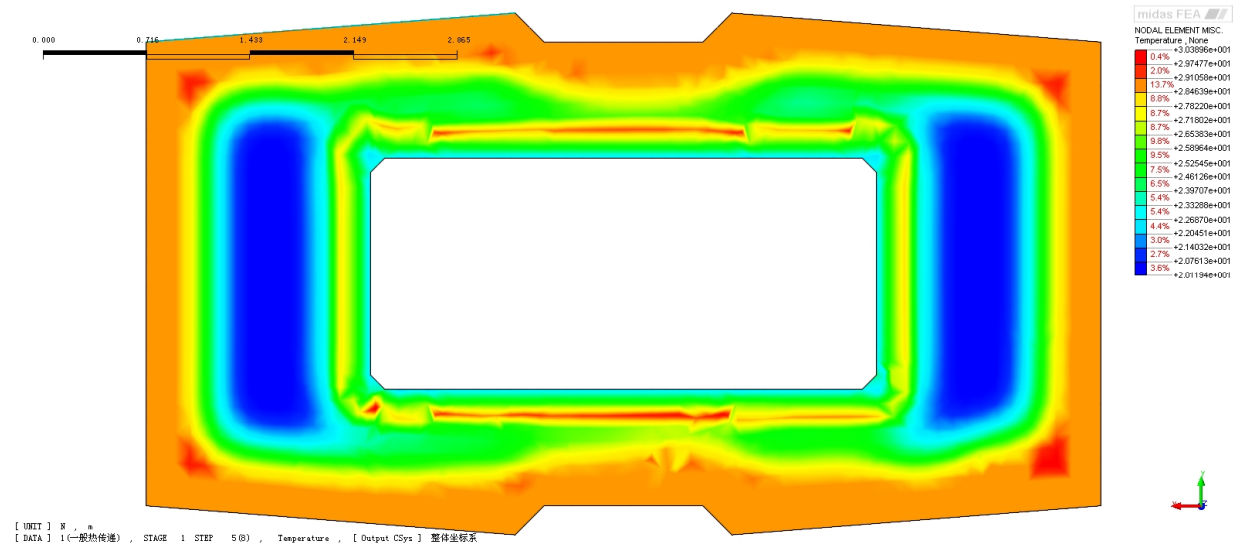

Fig.4 the heat conduction temperature distribution of main pier

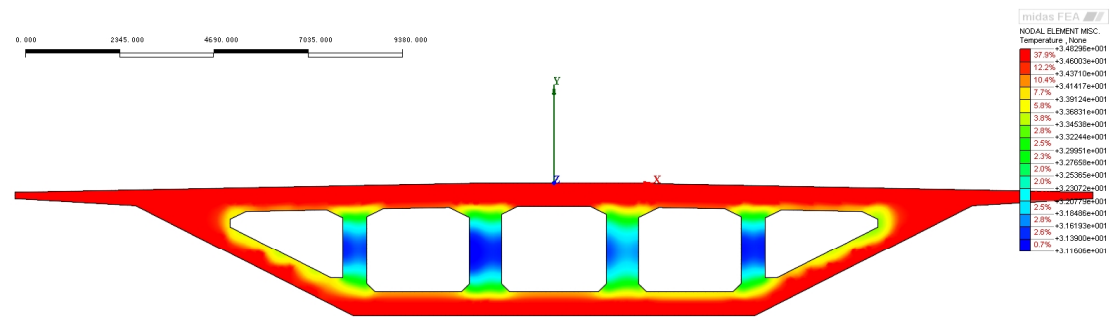

Fig.5 temperature distribution of main beam

The contrast in Fig.4 and Fig.5 shows little effect on the thermal conductivity of concrete $\pi$-beam with the change of the temperature field

In summary, when the temperature field of concrete beam is made provision of the temperature gradient, and no detailed thermal properties of concrete parameters are measured.

\section{Conclusion}

In this paper, the temperature field of Yamen Bridge is analyzed, and the influence of temperature field is as follows: 
The existence of time lag relationship in the plate temperature field is proved by theoretical analysis of internal and external surfaces, and period of the concrete temperature variation with temperature cycles are the same; thermal physics of concrete wind speed has little effect on the nature and type of the main beam of concrete temperature field.

\section{Acknowledgements}

The project surported surported (No.20140080089566) from Department of communication of Jiangmen.

\section{References}

[1]. Kenneth W. Design of segmental bridges for thermal gradien. PCI Journal, July-August: 120-137. (1998)

[2]. Tong M,Tham L G, Au F T K, et al. Numerical Modelling for Temperature Distribution in Steel Bridges. Computers and Structures. (2001)

[3[. Man Tong, Leslie G Tham, Francis T. K. Extreme Thermal Loading on Steel Bridges in Tropical Region. Journal of Bridge Engineering. (2002)

[4[. BS5400:Part2:1978, Steel, concrete and composite bridges. British Standard Institute, (1978)

[5]. LRFDSI-3, AASHTO LRFD Bridge design specifications. American Association of State High and Transportation Officials, (2004).

[6]. Roeber, C. W. Proposed design method for thermal bridge moments. Journal of Bridge Engineering, ACSE, (2003).

[7]. Lucas J M,Virlogeux M,Louis C. Temperature in the box girder of the normandy bridge. Structural Engineer. (2005)

[8]. H. C. Fu,S. F. Ng,M. S. Cheung.Thermal behavior of composite bridges. Journal of Structural Engineering (1990).

[9]. Larsson O,Thelandersson S.Estimating extreme values of thermal gradients in concrete structures. Materi-als and Structures. Materials and Structures, (2011).

[10]. Muneer T, Gui M S. Evaluation of sunshine and cloud cover based models for generating solar radiation data. Energy Conversion and Management, (2000).

[11]. Barsotti R,Froli M.Statistical analysis of thermal ac-tions on a concrete segmental box-girder bridge. Structural Engineer, (2000)

[12] Thomas N.Sveinson, Temperature Effects in Concrete Box Girder

Bridges .The Degree of Doctor of Philosophy in Civil Engineering of

University of Calgary , August, (2004) 